\title{
KARAKTERISTIKE PACIJENATA SA OPERATIVNO TRETIRANIM HIDRCEFALUSOM
}

\author{
THE CHARACTERISTICS OF PATIENTS WITH A SURGICAL OPERATION OF HYDROCEPHALUS
}

\author{
Vesna Ivanišević, Mišo Miškić, Peđa Kovačević, Danica Momčićević, Saša Dragić
}

\section{Sažetak}

Uvod: Hidrocefalus je hidrodinamički poremećaj toka cerebrospinalnog likvora gdje dolazi do proširenja komornog sistema i povećanja pristiska na mozak. Tretman je uglavnom hirurški.

Ciljevi: Utvrditi zastupljenost pojedinih tipova hidrocefalusa po toku i uzroku, analizirati dobnu $i$ polnu zastupljenost, te diskutovati najvažnije nalaze.

Materijal i metode: Riječ je o retropektivnoj studiji nastaloj na osnovu analize podataka o hirurškom liječenju pacijenata od hidrocefalusa u Službi za neurohirurgiju Univerzitetskog kliničkog centra Republike Srpske u 2017 i 2018 godini.

Rezultati $i$ diskusija: U našem uzorku nešto je veća zastupljenost hroničnih formi hidrocefalusa (53.8\% vs 46.2\%). U najvišem procentu se radilo o obstruktivnom hidrocefalusu (84\%), dok je učestalost kongentialnog hidrocefalusa zabilježena u $2 \%$ slučajeva.

Zaključak: Hidrocefalus uglavnom zahtjeva hirurški tretman, te je uvijek prije svake odluke neophodna korelacija svih dostupnih podataka i parametara kao i dalji adekvatan nadzor od strane neurohirurga. šant.

Ključne riječi: hidrodinamički poremećaj, povišen intrakranijalni pritisak, ventrikulo-peritonealni
\end{abstract}

\section{UVOD}

Hidrocefalus je patološko stanje koje uključuje mnogobrojne varijacije i uvijek je okaraterisan povećanjem količine cerebrospinalnog likvora koji je bio ili jeste pod povećanim pritiskom. Radi se o hidrodinamičkom poremećaju zbog čega dolazi do povećanja zapremine prostora ispunjenog ovom tekućinom. Kao posljedica toga povećan je pritisak na zidove moždanih komora što rezultira moždanim oštećenjem [1]. Kod odraslih osoba, obzirom da su kosti lobanje većim dijelom srasle, nakupljanje likvora brže dovodi do povišenog pritiska unutar lobanje nego kod novorođenčadi gdje usljed nesraslih sutura dolazi do uvećanja lobanje i karakterističnog izgleda glave [2-4]. Prekomjerno nakupljanje cerebrospinalne tečnosti unutar komornog sistema mozga izazvano je poremećajem njene sekrecije, toka ili pak apsorpcije. Cerebrospinalni likvor se nalazi u moždanim komorama u cisternama oko mozga, u centralnom spinalnom kanalu i u subarahnoidnom prostoru oko mozga i kičmene moždine. Ventrikularni sistem mozga sastoji se od dva lateralna ventrikula te trećeg i četvrtog ventrikula smještenih u središnjoj liniji i povezanih aqueductusom cerebri. Cerebrospinalna tečnost, koju luči plexus choroideus ventrikula, puni ove moždane komore $\mathrm{i}$ subarahnoidni prostor između mozga i kičmene moždine. Cerebrospinalna tečnost napušta lateralne ventrikule kroz foramen intraventriculare i ulazi $\mathrm{u}$ treći ventrikul. Odatle prolazi kroz aqueductus cerebri u četvrti ventrikul. Dio cerebrospinalne tečnosti napušta ovaj ventrikul kroz medijalni i lateralne otvore i ulazi u subarahnoidni prostor, koji je kontinuiran oko kičmene moždine i posterosuperiorno oko malog mozga. Glavno mjesto apsorpcije CSF u venski sistem je kroz arahnoidne granulacije, posebno one koje se probijaju u sinus sagittalis superior i cerebrospinalna tečnost ulazi u venski sistem. Ljudsko tijelo dnevno proizvede oko 500 - $570 \mathrm{ml}$ cerebrospinalne tečnosti (likvor) dok je njena zapremina od $50 \mathrm{ml}$ kod beba do $150 \mathrm{ml}$ kod odrasle osobe. U normalnim uslovima postoji osjetljiva ravnoteža između brzine kojom se proizvodi i brzine kojom se apsorbuje, a 
hidrocefalus nastaje kada je ova ravnoteža poremećena tako da je brzina apsorpcije manja od brzine nastajanja likvora [5-7]. Likvor ima značajnu ulogu da amortizuje inercione efekte djelovanja mehaničke sile na lobanju, tako da mozak jednostavno lebdi u tečnosti. Osim toga, likvorom se odvija i cirkulacija neophodnih, hranljivih supstanci i neurotransmitera [8]. Kod novorođenčadi i dojenčadi glavna dijagnostička metoda je ultrazvuk mozga gdje se kroz fontanele obavlja snimanje. Nakon zatvaranja fontanele dijagnostika se provodi pomoću magentske rezonance (MR) ili kompjuterske tomografije (CT), a dijagnostici hidrocefalusa MR daje mnogo bolji prikaz mozga i mogućeg uzroka hidrocefalusa [9]. Znakovi koji ukazuju na hidrocefalus su: proširenje ventrikularnog sistema koje ne pripisujemo moždanoj atrofiji, periventrikularna hipodenzna zona na CT ili povišenje signala na T2W1 na MR, transependimalnu apsorbciju likvora $\mathrm{i}$ zaokruživanje, baloniranje frontalnih rogova (Slika 1) $[9-10]$.

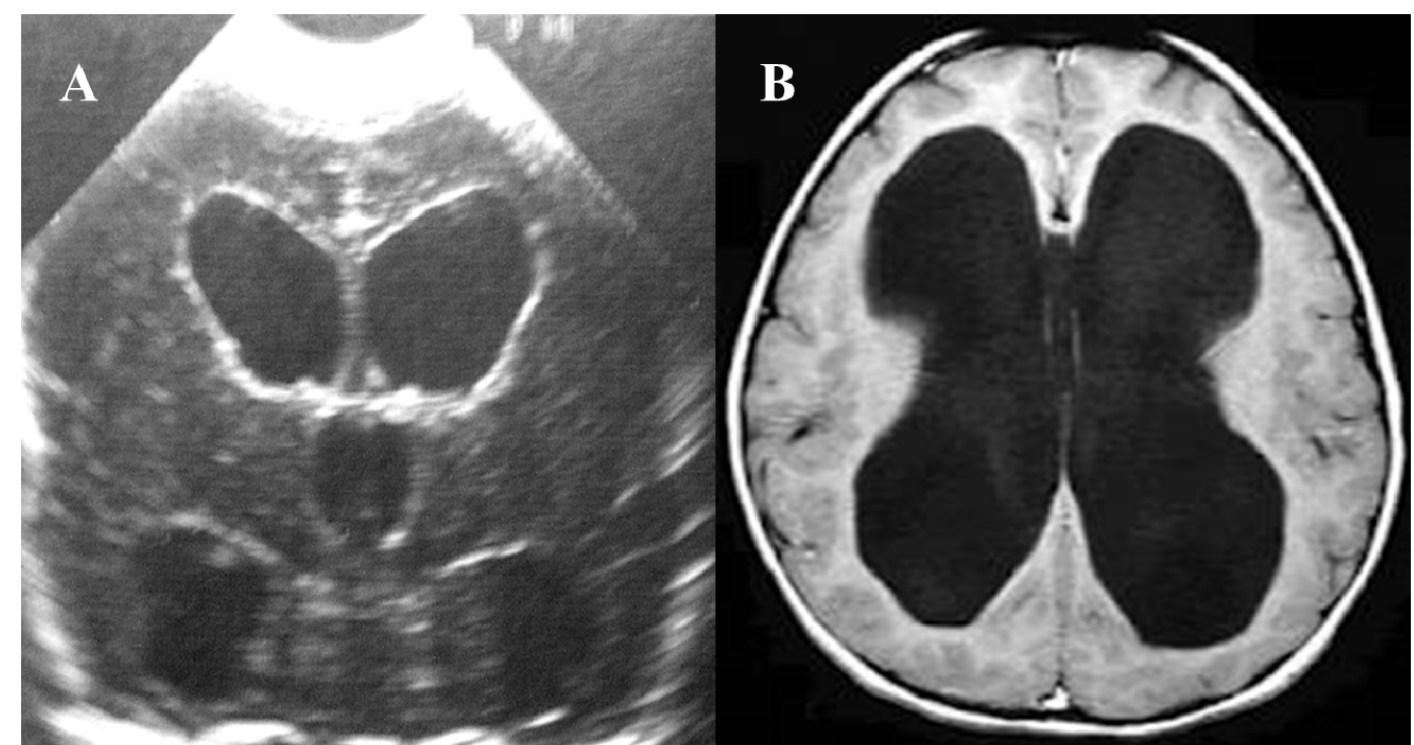

Slika 1. Dijagnostika hidrocefalusa - Ultrazvuk (A) i MR (B) endokranijuma kod djeteta sa posthemoragijskim hidrocefalusom

Picture 1. Diagnostics of hydrocephalus - Ultrasound (A) and MR (B) endocranium in a child with posthemorrhagic hydrocephalus

Zahvaljujući CT snimcima moguće je utvrditi veličinu i položaj moždanih komora, veličinu subarahnoidnog prostora na bazi i konveksitetu mozga kao i prisustvo ili odsustvo nakupljene tečnosti oko mjesta opstrukcije likvora. Stenoza akvedukta se dijagnostikuje na osnovu dilatacije bočnih i III moždane komore udružene sa smanjenom ili normalnom IV komorom i ponekad proširenim proksimalnim dijelom akvedukta [11]. Simptomi koji se javljaju kod hidrocefalusa zavise od dobi pacijenta, brznine kojom se hidrocefalus razvija kao $\mathrm{i}$ od uzroka koji do njega dovodi. Liječenje hidrocefalusa zavisi od uzroka jer je problem nakupljanja likvora izlječiv, dok primarni uzrok nastanka hidrocefalusa ne mora biti [12].
Hirurško liječenje hidrocefalusa podrazumijeva odstranjenje likvora iz mozga i njegovog preusmjeravanja. Operativni tretman podrazumijeva unutrašnje (ventrikuloperotoneostomija ili ventrikuloatriostomija) i vanjske drenaže (eksterni ventrikularni dren) [13].

\section{MATERIJAL I METODE}

Riječ je o retrospektivnoj analizi podataka iz arhiva Univerzitetskog kliničkog centra Republike Srpske. Klinički materijal čine pacijenti koji su hirurški liječeni zbog hidrocefalusa u Službi za neurohirurgiju u toku 2017 i 2018 .godine, a rezultati su predstavljeni tabelarno i grafički. 


\section{REZULTATI}

Tabela 1 pokazuje distribuciju po toku bolesti, dobi i polu.

\begin{tabular}{|c|c|c|c|}
\hline & & Broj pacijenata & $\%$ \\
\hline \multirow{2}{*}{ Tok } & Akutno povišen intrakranijalni pritisak & 24 & $46,2 \%$ \\
\hline & Hronično povišen intrakranijalni pritisak & 28 & $53,8 \%$ \\
\hline \multirow{7}{*}{ Starost } & $<15$ godina & 6 & $11,5 \%$ \\
\hline & $16-25$ godina & 5 & $9,6 \%$ \\
\hline & $26-35$ godina & 3 & $5,8 \%$ \\
\hline & $36-45$ godina & 7 & $13,5 \%$ \\
\hline & $46-55$ godina & 13 & $25,0 \%$ \\
\hline & $56-65$ godina & 8 & $15,4 \%$ \\
\hline & $>66$ godina & 10 & $19,2 \%$ \\
\hline \multirow{2}{*}{ Pol } & muškarci & 22 & $42,3 \%$ \\
\hline & žene & 30 & $57,7 \%$ \\
\hline
\end{tabular}

Tabela 1. Distribucija po toku bolesti, dobi i polu

Table 1. Distribution by the course of the disease, age and gender

Grafikon 1 predstavlja zastupljenost pacijenata $\mathrm{u}$ uzorku prema vrsti hidrocefalusa.

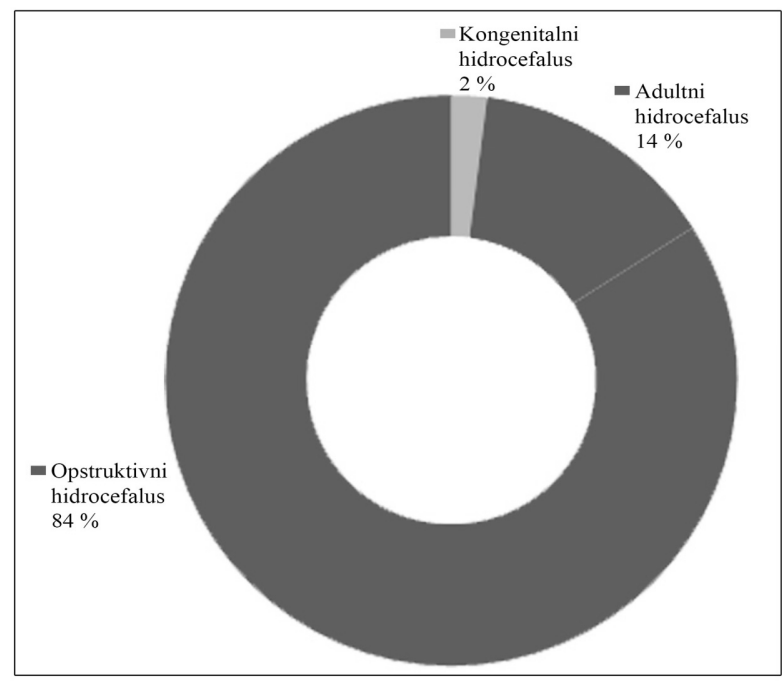

Grafikon 1. Zastupljenost pacijenata u uzorku prema vrsti hidrocefalusa

Graph 1. Representation of patients in the sample by type of hydrocephalus

\section{DISKUSIJA}

U ukupnom uzorku pacijenti sa akutno razvijenim hidrocefalusom predstavljaju $46.2 \%$, dok su pacijenti koji su hronično razvili hidrocefalus zastupljeni u 53.8 $\%$ slučajeva. Uzimajući u obzir dobnu distribuciju vidimo da je kod oko četvrtine neurohirurških intervencija hidrocefalusa (25 \%) izvršeno na pacijenatima starosti 46 do 55 godina, dok je nešto manje pacijenata (19,2\%) bilo starijih od 66 godina. Najmanje neurohirurških intervencija hidrocefalusa je izvršeno kod pacijenata starosti 26 do 35 godina $(5,8 \%)$ i onih starosti 16 do 25 godina $(9,6 \%)$. Posmatramo li polnu strukturu pacijenata sa hidrocefalusom vidimo da je više žena $(57,7 \%)$ nego muškaraca $(42,3 \%)$, što takođe odgovara dostupnim literaturnim podacima. Rezultati našeg istraživanja takođe ukazuju na višu zastupljenost opstruktivnog tipa hidrocefalusa $(84 \%) \mathrm{u}$ odnosu na hidrocefaluse uzrokovane drugim faktorima. Takav odnos se takođe slaže sa podacima iz dostupne medicinske literature. U nekim istraživanja postotak zastupljenosti opstruktivnog hidrocefalusa u uzorku ide i do $90 \%$. Sa druge strane, zastupljenost kongenitalnog hidrocefalusa (2\%) je najniži bez obzira što je ta vrsta hidrocefalusa prihvaćena kao sinonim za ovaj patološki entitet.

Kongenitalni ili primarni hidrocefalus javlja se sa incidencom od 1 slučaja na 1000 živorođenih i obično je sporadičnog karaktera. Hidrocefalus se može javiti ili kao izolovan klinički entitet ili u sklopu sindroma kompleksne kongenitalne malformacije. Familijarna forma u kojima se hidrocefalus nasleđuje preko $\mathrm{X}$ hromozoma po autonomno recesivnom modelu ima incidencu od 1 slučaj na 30.000 živorođene muške djece i smatra se da ova forma kongenitalne hidrocefalije čini $25 \%$ svih slučajeva hidrocefalusa kod muške djece. Najveći broj prerano rođene djece razvije hidrocefalus kao rezultat intraventrikularne hemoragije. Kod terminskih neonatusa, hidrocefalus je obično rezultat raznih genetskih defekta ili je udružen sa njima. Drugi razlog je evidentno sve veće 
preživljavanje veoma malih prematurusa. Incidenca intraventrikularne hemoragije kod novorođenčadi čija je porođajna tjelesna masa od 500 do 749 gr prosječno iznosi $45 \%$. Ipak najeveći broj pacijeneta sa hidrocefalusom je u onoj skupini čiji su uzrok patološki supstrati koji se nalaze u blizini komornog sistema mozga kao i oni tumori koji se razvijaju unutar komornog sistema (ependimomi, pleksus papilomi, koloidne ciste, pinealomi) koji mogu mehanički kompromitovati cirkulaciju likvora izazivajući opstrukciju i unutrašnji hidrocefalus [14].

Uzrok skoka intrakranijalnog pritiska, kod patoloških procesa u zadnjoj lobanjskoj jami skoro uvijek je opstrukcija protoka cerebrospinalnog likvora zbog patološkog procesa i razvoja hidrocefalusa. U zavisnosti od korelacije između kliničke slike i radiološkog nalaza $\mathrm{CT}$ ili $\mathrm{MR}$, kao i oftalmološkog pregeda - nalaz fundusa, postavlja se indikacija za ugradnju sistema za drenažu likvora, ili punkciju okcipitalnog roga lateralne moždane komore nakoliko dana prije operativnog zahvata koji podrazumijeva odstranjenje ili redukciju patološkog supstrata. Postoje i slučajevi gdje je indikovano postavljanje privremenog drenažnog sistema, na primjer kod slučajeva krvarenja u komorni sistem, gdje koagulumi mogu praviti opstrukciju normalnog protoka likvora. Privremeni sistem za drenažu likvora vadi se nakon što se likvor izbistri, a normalna cirkulacija likvora uspostavi ili se zamjenjuje zatvorenim sistemom za drenažu najčešće ventrikulo - peritonealnim.

Najbrojniju skupinu u našem uzorku čine operativno tretirani pacijenti sa opstruktivnim hidrocefalusom kod kojih u osnovi smetnje protoka likvora leži primarni patološki supstrat bilo da se radi o krvarenju, tumoru ili priraslicama nakon infekcije.

Bez obzira koliko jednostavno izgledale tehnike kojima se liječi hidrocefalus, treba imati na umu da je to jako kompleksno oboljenje sa veoma velikim brojem komplikacija. Zbog toga je važno da se razlikuje proširenje komora nastalo zbog hidrodinamskog disbalansa (pravi hidrocefalus) od dilatacije nastale usljed atrofije (hydrocephalus ex vacuo). U ovom drugom slučaju, modifikovanje hidrodinamike u lobanjskoj šupljini ne može dovesti do reverzije hidrocefaličnog procesa. Atrofija mozga takođe vodi ka proširenju komora, dok povećan pritisak likvora u slučaju primarnog hidrocefalusa ima proširenje komora kao svoj sekundarni negativni efekat. Zbog toga mogućnost i stepen poboljšanja nakon šant-operacija kod hidrocefalusa zavisi od već stvorenih simptoma hidrocefalusa određenih hidrauličkim pritiskom u vidu sekundarnih efekata komorske dilatacije. Najčešće se koristi ventrikuloperitoneostomija kao metoda liječenja hidrocefalusa. Osim toga, postoje i privremene metode za redukciju volumena likvora i povišenog intrakranijalnog pritiska, kao što je plasiranje vanjske ventrikularne drenaže. Obzirom na veliki broj komplikacija kao i na činjenicu da se radi o ugradnji stranog materijala postoje bazični uslovi u pogledu sterilnosti likvora koji moraju bit zadovoljeni prilikom postavljanja indikacije za ugradnju sistema za drenažu [15].

\section{ZAKLJUČAK}

Najzastupljeniji tip hidrocefalusa u našem uzorku, bilo da se radilo o ugradnji trajne ili privremene drenaže je opstruktivni tip hidrocefalusa. Obzirom da je hidrocefalus veoma kompleksno stanje neophodno je u svakom individualnom slučaju razmotriti sve dostupne parametre prije donošenja odluke o ugradnji sistema za drenažu. Pojava kongenitalnog novorođenačkog hidrocefalusa je smanjena širokom upotrebom ultrazvuka u praćenju trudnoće, ali je opstruktivni novorođenački hidrocefalus kod prematurusa povećan, vjerovato zbog visokog procenta intrakranijalne hemoragije kod prematuriteta.

\section{LITERATURA}

1. Rekate HL. A consensus on the classification of hydrocephalus: its utility in the assessment of abnormalities of cerebrospinal fluid dynamics. Childs Nerv Syst. 2011;27:1535-41.

2. Kristensen B, Malm J, Fagerland M, Hietala SO, Johansson B et al. Regional cerebral blood flow, white matter abnormalities, and cerebrospinal fluid hydrodynamics in patients with idiopathic adult hydrocephalus syndrome. J Neurol Neurosurg Psychiatry. 1999;60(3):282-8.

3. Fishman MA. Hydrocephalus. In: Neurological pathophysiology, Eliasson SG, Prensky AL, Hardin WB (Eds), Oxford, New York 1978.

4. Lee SC, Lueck CJ. Cerebrospinal fluid pressure in adults. J Neuroophthalmol 2014; 34:278-81.

5. Kulkarni AV, Riva-Cambrin J, Rozzelle CJ, Naftel RP, Alvey JS et al. Endoscopic third ventriculostomy and choroid plexus cauterization in infant hydrocephalus: a prospective study by the Hydrocephalus Clinical Research Network.J Neurosurg Pediatr. 2018;21(3):214-23. 
6. Graff-Radford NR, Knopman DS, Penman AD. Do systolic BP and pulse pressure relate to ventricular enlargement? Eur J Neurol 2013;20:720-43.

7. Marshall LF. Head Injury: recent past, present, and future. Neurosurgery 2000;47:546-61.

8. Savolainen S, Laakso MP, Paljärvi Let. MR imaging of the hippocampus in normal pressure hydrocephalus: correlations with cortical Alzheimer's disease confirmed by pathologic analysis. AJNR Am J Neuroradiol 2000;21:409-19.

9. Tullberg M, Jensen C, Ekholm S, Wikkelso C. Normal pressure hydrocephalus: vascular white matter changes on MR images must not exclude patients from shunt surgery. AJNR Am J Neuroradiol 2001;22:1665-83.

10. Hakim R, Black PM. Correlation between lumboventricular perfusion and MRI-CSF flow studies in idiopathic normal pressure hydrocephalus. Surg Neurol 1998;49:14-7.

11. Dewan MC, Lim J, Gannon SR, Heaner D, Davis MC, Vaughn B, Chern et al. Comparison of hydrocephalus metrics between infants successfully treated with endoscopic third ventriculostomy with choroid plexus cauterization and those treated with a ventriculoperitoneal shunt: a multicenter matchedcohort analysis. J Neurosurg Pediatr. 2018; 21(4):33945 .

12. Kang K, Ko PW, Jin M, Suk K, Lee HW. Idiopathic normal-pressure hydrocephalus, cerebrospinal fluid biomarkers, and the cerebrospinal fluid tap test.J Clin Neurosci. 2014; 21(8):1398-403.

13. Warf BC, Bhai S, Kulkarni AV, Mugamba J. Shunt survival after failed endoscopic treatment of hydrocephalus. J Neurosurg Pediatr. 2012;10(6):46370 .

14. Weiner HL, Constantini S, Cohen H, Wisoff JH. Current treatment of normal-pressure hydrocephalus: comparison of flow-regulated and differential-pressure shunt valves. Neurosurgery 1995; 37:877-99.

15. Pujari S, Kharkar S, Metellus P. Normal pressure hydrocephalus: long-term outcome after shunt surgery. J Neurol Neurosurg Psychiatry 2008;79:1282-91.

Summary:Introduction: Hydrocephalus is a hydrodinamic disorder of cerebrospinal liquor with consequence of dilatation of coronary system and increase of pressure on brain. The treatment is mainly surgical.

Aims: To establish the presence and process of certain types of hydrocephalus and to analyse age and gender representation, and discuss the most important findings

Material and methods: This is a retrospective study based on data analysis of the surgical treatment of patients with hydrocephalus in Department of neurosurgery at University Clinical centre in The Republic of Srpska in 2017/2018.

Results and discussion: In our sample the biggest amount were the chronic forms of hydrocephalus $(53.8 \%$ vs $46.2 \%)$. The highest percentage was the obstructive hydrocephalus (84\%) till the frequency of the congenital hydrocephalus was recorded in $2 \%$ of the cases.

Conclusion: The hydrocephalus almost always needs the surgical operation. Also before any decision it is necessary to make correlation of all available data and parameters, and also adequate supervision of a neurosurgeon.

Key words: hydrodynamic disorder, increased intercranial pressure, ventriculoperitoneal shunt

Doc. dr sc. med. Vesna Ivanišević

Služba za neurohirurgiju

Telefon: +38765 510779

E-mail:vesna.ivanisevic@kc-bl.com 